\title{
Systematization: The Effective Way to Learning and Achieving Competence of the English Language
}

\author{
Faramarz Samifanni* \\ Fukuoka International University of Health and Welfare \\ T814-0001, Fukuoka Prefecture, Fukuoka city, Sawara Ku, Momochihama 3-6-40, Japan \\ * E-mail of the corresponding author: fredsami@takagigakuen.ac.jp
}

\begin{abstract}
This article aims to show that systematization is the final stage of any language learning through grammar competence, reading, and writing. Even if it is the new language being learned, systematization is the conceptualization and the formation of meaning based on the learner's native or mother language and adjusted to 'the target language', and creation of new words. The data mining technique was utilized to validate the hypothesis generated. Results reveal that Systematization is a combination of prescriptive and descriptive grammar in the sense that a language learner has to learn the structure and function of grammar in achieving the accuracy of the target language. A learner's native language can also take a big part in the formation of various concepts and meanings in learning the language. Moreover, tone and inflection put the meaning across because the way how things are said or written greatly affects the meaning of the statement. When all considerations are met, a language learner reaches the point of forming new words out of his language faculty. Thus, systematization in language learning is the optimum level of achieving fluency, accuracy, and competence of the target language where the learner could manifest language mastery at its best.
\end{abstract}

Keywords: accuracy, competency, inflection, language learning, systematization

DOI: $10.7176 / \mathrm{JEP} / 11-14-03$

Publication date:May $31^{\text {st }} 2020$

\section{Introduction}

Learners of the English language can only be considered successful when they have reached "accuracy and fluency" in applying the new or target language. West (2016) stressed that accuracy means "the aptitude to produce correct sentences in using proper grammar and vocabulary." Meanwhile, fluency defines "the ability to construct language simply and smoothly."

Accuracy is considered reciprocal to learning. A child's level of accuracy is far from that of an adult. It is common for a young learner to use faulty words. "Teachers, who concentrate on accuracy help their learners to make grammatically accurate written and vocal English, preferably aim towards the accuracy of a native speaker of parallel age and background. The focus in the classroom will be on sentence structure presentations and exercises, reading conception and systematization"; this is prescriptive grammar (West, 2016).

West (2016) further illustrated that a fluent non-native speaker might commit grammatical mistakes but will converse or write well (free of gaps). He or she can communicate freely and talk with native-speakers about anything under the sun. As non-native speakers improve and become more at ease in using the target language, their fluency level also increases. Language instructors who focus on fluency help learners to better express themselves using English or the target language and pay close attention to meaning and context than errors in grammar. Therefore, starting a language learning strategy with grammar may have a very negative impact as many Japanese elders would quickly agree that their English teachers at school severely emphasized accuracy, and grammar and writing were the focus of their school curricula (what sounds most-likely the Grammar Translation Method).

In learning a language, any learner's main goal is to achieve fluency and accuracy, thus it is vital to realize the importance of knowing and applying the system of rules of a language. Harmer's (2001) study revealed that learners must be aware of "language features" and its application in communication. When the teacher has the mastery of these features, the learners will easily grasp and achieve the goal of communication. Speaking does not only require linguistic feature knowledge; in oral communication, the application of these features "involves more than memorized words and grammatical knowledge." One of the challenges in verbal communication classes is "inconsistency between classroom resources and courses, where the majority of instructors do not create a setting for a real performance of verbal communication; also, the instructor should consider the learners' interests and needs." Moreover, students must be actively engaged in speaking tasks to naturally share their thought using the target language (Derakhshan, Tahery, \& Mirarab, 2015). Therefore, the teacher or instructor's role is very important in directing the learner in the target language.

\subsection{Literature Review}

Language, as defined by Harley (2001), is a "system of symbols and rules" that allows human beings to 
communicate. The codes or "symbols" used in language can include speech sounds as well as writing; while the rules include grammar (e.g. adverb, tense), structure, and pragmatics. There is an arbitrary relationship between a linguistic symbol and its referent. The language provides the context for symbolic understanding. The use of language is intimately connected to cognition.

Haiman (2002) noted that "language has its 'systematicity' as one of its unique features: to a great degree, grammar rules relate only to other rules and not to the world outside. Grammar rules exist autonomously from outside influences. The idea of systematization refers to a process wherein such regulations have evolved from pre-systematic outwardly forced genesis."

It is possible to learn to speak foreign languages very well without a degree in linguistics, but there are a few things that linguists and language teachers can teach us. Language studies usually also involve courses in grammar and vocabulary as well as conversation classes with a native teacher (Sharma, 2017). Interaction using the target language is important.

Language is composed of "systems and skills," phonology, vocabulary, grammar, and speech are the four integrated systems of language. The most vital and essential factor in communication is language. Without language, people cannot convey information to another person. There are many types of languages such as oral language, written language, body language, gesture, etc. However, language also has some features such as grammar and vocabulary (Yulianto, 2014).

One of the learners' difficulties in learning English is that they cannot produce correct or meaningful sentences. They cannot produce it because they do not understand the grammar of the sentence. Once learners understand how a language is structured and how it functions, it is a lot easier to learn other languages as well (at least those belonging to the same language family) (Sharma, 2017). The researcher thinks that syntax is important to be discussed because it is related to sentence structure. A good sentence structure is needed to form meaningful information to another person.

\subsection{Research Objective}

This study aimed to describe how understand and achieve competence in the English language through systematization.

\section{Material and Methods}

This section comprises the research design, sources of data, data-gathering procedure/ theory generation, coding and categorizing, and theoretical sampling/ theory confirmation.

\subsection{Research Design}

This article employed a mixed qualitative method; deductive- axiomatic design to generate a theory (Arnold, Arnold, \& Arnold, 2010; Zalaghi \& Khazaei, 2016) as described in the lived experiences of the author about a phenomenon; English language (Creswell, 2013). A deductive- axiomatic procedure begins with the general principles and ends with specific statements, which can be best used for arguments based on laws and other widely accepted principles (Arnold, Arnold, \& Arnold, 2010; Zalaghi \& Khazaei, 2016).

\subsection{Sources of Data}

This study used desk research and the author's lived knowledge and observations.

\subsection{Data-gathering Procedure/ Theory Generation}

The theory development involved the formulation of the set of axioms based on the analyses of different references and diverse literature on language learning. Afterward, propositions were formulated after creating the connections amongst the axioms. Then, the author's lived knowledge and observations were used to verify the arguments.

The pre-mining tasks involving data cleaning which involved removing irrelevant and undependable information, and data integration that concerns the accumulation of facts from several sources to a particular location and a shared format.

Consequently, are the post-mining tasks involving evaluation focusing on pattern identification that represents knowledge, and knowledge presentation which provides discovered rules through visualization and various knowledge portrayal methods.

\subsection{Coding and Categorizing}

Like any other studies using deductive axiomatic process in theory development, the axioms and propositions were derived after open coding. In this process of coding and analysis, the researcher attempts to consolidate the data through constant comparison and some deductive relations. 


\subsection{Theoretical Sampling/ Theory Confirmation}

In this stage, the researcher saved, encrypted, and evaluated the information mined then analyzed which truths must merge to create axioms and propositions. The emerging and selected axioms will give more direction to create propositions. The criteria of theoretical purpose and relevance were applied and to the ongoing data analysis at the same time as the theory is being built deductively. This method ensures the data's relevance to the emerging theory. The data mining technique was used to validate the generated theory in this study.

\subsection{Theory Generation Process}

The theory generation process is shown below.

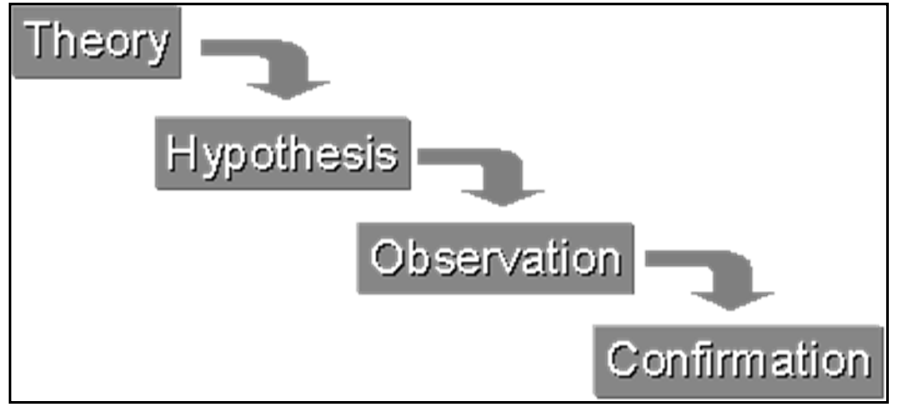

Figure 1. Theory Generation Process (Glasser, 1978)

\subsubsection{Axioms}

Axiom 1: One's native language influences thought, memory and perception.

Axiom 2: Language and culture are interrelated and used as tools.

Axiom 3: People are born with the tools to learn and develop language through time.

Axiom 4: Language learning requires meaningful interactions.

Axiom 5: Language is learned through Communication and social construction that frames the properties of cultural identity.

2.6.2 Proposition

Language can be developed with variations in the context of social settings, culture, time and space.

\subsection{The Theory}

Systematization is the concluding phase once the localization of the cultural part is understood, the imitation is accepted and practice has enhanced. The learner now needs to systematize the learning procedure through the studies of the tangible language and focus on reading, writing, grammar, and other points as actual skills. Some may ask why leave these at the end and why not in the beginning? The fact is that learning any language observation (learning the culture) is first and using the senses to attempt to comprehend is secondary while in the tertiary stage imitation takes place. The baby does not read and write and study grammar before speaking. Observing and learning to speak are the first steps to language learning. Systematization means to begin a more serious interest in learning a targeted language.

Once aware and equipped with localization of the target language, imitation of the phonology, practice of the usage and structure of the language, it is now time to put those skills into practice and apply it constantly in reallife context with an open mind for error correction; one can then be called fluent in the target language. However, it does not stop there. Syntax and diction get into the picture for an accurate speaker. Therefore, language learning requires localization, imitation, practice, and systematization to transfer from fluency and achieve accuracy in the target language.

\section{Result}

This research is based on the pragmatic thought that society is formed as a result of an individual's need to survive and to belong. In such unities, groups are formed into society; and informing society, culture is shaped. For culture to advance, language is created for the members of the society to communicate with one another. Therefore, culture came first and not the other way around. Culture is the motivator and force behind a language and without it, language does not even need to exist. In this research, it has been proven that other than language, some additional ways or tools affect communication such as tones, gestures, and many more. But the purpose of this study is to show with much evidence; the great impact culture has on language learning. Language learning is using language as a tool for communication. Therefore, for a learner to learn a language in its proper context and form, the learner requires massive knowledge of the local culture; then imitates and practice the language used by that society. The joy of learning is in the active participation of communicating; it is only then that a learner will get interested in wanting to systematize the language he or she has indulged in. 


\section{Discussion}

English is called the world's leading global language', for the reason that it is used as the medium of communication in almost all sectors of human life as seen in politics, science, and commerce (Crystal, 2003). When people hear the word 'English', they think it is a globally standard language. While it may be used globally, it cannot have a global standard.

\subsection{Understanding the rules grammar and syntax}

With grammar being the unbreakable guidelines of any language; Larsen-Freeman (2001) labeled it "a system of meaningful structures and patterns that are ruled by specific pragmatic limitations". If grammar is removed, Azar (2007) clarified; people would communicate like 'Tarzan' using words, phonemes, pictures, and gestures. "Grammar is the weaving that creates the fabric". It is important to have a working grammatical knowledge enable to create exact and accurate sentences. Another notion is written by Ellis (2006) on the significance of grammar: "Teaching grammar comprises any technique that draws the learners' attention to a specific grammatical structure that helps them either to fully understand in a metalinguistic sense or perfectly apply its rules".

Language learning, emphasized Richards \& Renandya (2002), in the absence of grammar could create confusion. Learners will fail to use the language correctly without grammar skills. It is widely agreed that grammar is indeed crucial in language study and learners without a good command of grammar, will have poor written and oral communication skills.

Grammar is regarded as the complete system of all languages (Beverly, 2007). Those who share a common language, communication is easy because the grammar system of that verbal communication is in their subconscious mind as a guideline of creating the meaning of the words collectively used by them. It is assumed that born-speakers of English understand its grammar and recognize its features (Chin, 2000).

Even if one is considered to be an effective speaker of English, guidance is still needed to become an effective writer. Learners must know how to transform these concepts from spoken to written discourse (Yulianto, 2014).

Indeed, people can still comprehend a sentence regardless of construction; that is, "even if individuals have not encountered a particular sentence in particular linguistic experience, they are nevertheless able to understand it because they can recognize familiar units (familiar words) combined in a novel but the appropriate way". However, learners cannot just memorize the entire vocabulary and expressions of the target language in a snap of a finger. "Their linguistics knowledge is characterized by its syntax with a fixed set of rules and principles regulating the language that shape the foundation for the learners' talent to create plus solve" countless expressions of the target language (Dwijatmoko, 2013).

Fluency takes a learner to a certain point in the society where a new language is used and the first three steps can take a learner from zero to absolute fluency for survival and clear communication. However, systematization is a must if one is to take a total immersion and proactively live within that society for the long-term. The researcher has his limitations in communication when it comes to explaining details or specific issues in Japanese due to his inability to read or write Japanese. Without formal Japanese lessons, he has been able to communicate fluently in Japan on a day to day normal basis. However, if one was to master the language, one has to systematically learn how to read and write and understand the proper usage of the grammar of the target language. Therefore, systematization is the final stage of language learning.

The syntactic relation is also an important part of learning grammar of the language because it talks about the relation from "word to word, word to a phrase, phase to clause and clause to sentence". Its main point is to establish a relationship among and between the words to successfully create a meaningful sentence when the words are in good order (Yulianto, 2014).

Language is not inborn and the researcher believes that human beings, after formulating society invented language as a means of communication. Just like any other tool used, language is an invention. Like metal, it rusts when it is not used, it passes away if unused and it changes in time through cultural changes from generation to generation. Therefore, it cannot be inborn or innate although grammar is highly important in achieving accuracy in the new or target language.

In Saaristo's (2015) study, university learners from Finland regarded grammar as "the heart of language" and an important part in learning any language. Parallel results were revealed in the perception of learners from America and Colombia. For these learners, grammar is an undeniable portion of learning another language (Schulz, 2001).

Moreover, the following studies support that "grammar awareness" helps improve learners' linguistic skills. Kun Hou and Na-Thalang (2013) claimed that language learners could advance their linguistic accuracy by "improving their awareness of the target linguistic structure". The investigation of (Nazari, 2013) exposed that focusing on the content improves the grammar structures of the learners. Explicit teaching strategy was found to be more effective, and informing learners of the grammatical rules makes them feel at ease, confident, and motivated to learn.

The ability of a learner to understand a sentence is a manifestation of his or her speaking proficiency in the 
target language, although it is strongly correlated with syntactic awareness and reading comprehension an output of one's proficiency in the native language; both are showing strong connections to "syntactic awareness and oral competence" (Lefrançois \& Armand, 2003).

Francis, Romo, \& Gelman (2002) obtained and examined manuscripts of intermediate-level English language class with embedded science instruction. They found that the grammar competence of learners has a great impact on the structure and content of their output.

Certainly, grammar competence is critical in achieving accuracy but is not an "absolute way" to language learning as a whole. Accuracy is about how learners correctly use the language. This includes learner's use of grammar, pronunciation, and vocabulary. When there is an issue on the learner's level of communication, accuracy is the stage after fluency. Nevertheless, grammatical accuracy must not be prioritized at the cost of fluency; language teaching should help learners to adopt "grammatical rules" for real-life applications and boost the learners' self-esteem to communicate verbally (Lee, 2005).

\subsection{Confusion with inflection}

Aside from grammar awareness, another factor that affects accuracy is the confusion caused by inflection. The manner of speaking is way more important than the message itself. Inflections can greatly impact the intended meaning and discussion. When orally reading a message or delivering a memorized speech, a lack of inflection will "give you away" very quickly and will bore the listeners or at worse be the cause of misunderstanding (Coleman, 2017).

As defined, inflection "is a change in the pitch of one's voice, while tone refers to the quality and strength of the vocal sounds". The absence of inflection and tone to the words would make the message 'dull and boring'. Fortunately, all languages contain these elements within the standards of their dialogues. "Tone and inflection" cannot be learned in a manuscript, "which is why it is very important to immerse and expose a learner in the environment" where he or she is learning a new tongue (Evan, 2016).

Results from a study conducted in 2011 revealed that "an average person can tell apart 1,378 obvious differences in tone. In contrast; people can differentiate just 150 shades of color. This is proof that hearing is 100 times more complex than our eyesight". Their research confirmed that "how you say something is five times more important than what you say" (Clark, 2018). Therefore, people can easily determine the meaning of the message if it is delivered using the right inflection and proper tone.

In public speaking, Miller (2009) highlighted that voice modulation or inflection "will help keep your audience awake and alert". Variance in tone to ask a question, express excitement, or even sadness will invigorate the gist of the message. He enumerates the kinds of inflection as follows:

"Upward inflection" occurs from a lower to a higher note within the vowel. This is an indication of a question, insincere remark, shock, or doubt; like "What?, Wow!, and really?" while "downward Inflection", occurs from a higher to a lower note within the vowel. Commonly indicating self-confidence, decisiveness, authority, and conviction; "done, no, go" are few examples. Another is "level inflection" where there is pitch monotony within the vowel showing disregard and dis-assurance in "OK, maybe, fine". Moreover "Double or Circumflex Inflection" is when there is a combination of pitch within the vowel. This generally shows "confidence, finality, power, and certainty in the words done, no, amazing" (Miller, 2009).

In writing, the tone is produced by the word's authors' choice in presenting their work creating an "attitude". Writers have to convey their meanings, depending on the purpose and the point, by "selecting specific words so that readers will comprehend their objective and accent" exclusive of the help of the verbal communication usage (Saint Joseph College, 2009). Examples of this would be the following:

Insincere: I am sorry to keep you waiting, but the physician was busy, and nothing could be done.

Sincere: I am really sorry to keep you waiting, but the physician had an emergency. Your patience is greatly appreciated.

Offensive: As Sam entered, Jo giggled and whispered: did your barber used a chainsaw to shave your head?

Candid: As Sam entered, Jo smiled and politely said, Wow! I love your nicely shaved head!

The tone could also fall among the following: Objective tone which shows no moods in favor of or opposition to anyone. The subjective tone is private, prejudiced, expressive, and frequently unceremonious. Pitch is conveyed through the language and information the writer chooses. It profoundly influences the way the learners' view and response to a passage (Strunk \& White, 2000) an example is:

Statement 1: Sam jumped out of the car, ran into the locker room, wore his swimwear, and ran towards the beach to swim with the dolphins.

Statement 2: Then Sam slowly drove the car, walked carefully to the locker room, reluctantly wore his swim gear and cautiously went towards the beach where killer-whales were swimming close to the beach. Whoa!

Statement one would imply that the subject (Sam) is happy to experience swimming with the dolphins while the second statement shows how the subject is disgusted by the fear of the appearance of killer-whales near the beach. 
In oral communication, intonation can reflect the meaning of a statement, and stressing elements of importance. This can express sociability, interest, or resentment; and listeners can the emotional state of the speaker like enthusiasm, sadness as well as exhaustion. A person can adjust a conversation through the use of intonation to indicate that he or she is done speaking or in another way he or she does not want to be interrupted (Nolan, 2014).

It is emphasized by Nolan (2014) that not only intonation but also pitch is used in languages; and that various languages employ pitch to differentiate words. Yucatec Maya, Thai, and Hausa words are distinguished speech sounds and particular pitch patterns or syllable emphasis; these are classified as "tone languages". However, Japanese (Nihongo) and Swedish languages have restricted pitch used to differentiate words; they are called lexical accent languages. Entirely, tone languages and lexical accent languages include pitch, but generally the more difficult would the use of pitch be for unique words, the simpler is intonation system found in a language. In other words, the more pitch is used in a language; their intonation is easier to understand. Because monotonic languages are more difficult to understand, especially when a learner does not understand the vocabulary just like the language of Cebuano the Philippines and the Cantonese of Hong Kong, China that sounds rough but can mean normal conversation. English, in contrast, does not fall to either classification and is normally known to rather have a complex intonation system. If the listener does not understand the meaning of the tone, intonation, and inflection than the message can be misunderstood.

During his stay in Cebu Philippines, the researcher lived across a neighbour who often speaks to her children and sounded like heavy screaming and answered back (by her children) screaming. This situation quite made the researcher worried that there are heavy fighting and child abuse in the neighbour's house. Rushing to other neighbour to ask for help to interpret the dialogue, they said that it is a normal conversation and not a fight or even an argument relieved the researcher. To the researcher's shock, the tone, intonation, and inflection of the Cebuano language are loudly based. Any newcomer who has been to a casual family dim-sum restaurant of Hong Kong would feel like he or she has just stepped into a food fight war zone with guests speaking to each other in a loud fashion when in reality they are just having a nice casual family conversation. This is due to the type of language based on tone, intonation, and inflection. Mastering requires avid learning and dedication to the process of systematization.

\subsection{Variations in pronunciation from high and low context cultures}

Japan being a silent society with an absolute rule on "Silence is Golden" has a language with a very little casual tone, intonation, and inflection. This does not mean that there are absolutely no tones. Japanese pronunciation is so important that the slightest change would change the entire meaning and mood. The word "Kawai" means "cute". Change Ka to Ko as in "Kowai" and the meaning changes to "scary". The more relevant word is "Ishi" or "Ishii" which used differently would mean different. As close as the word sounds, the learner must know the grammar usage to distinguish the relevant meaning. The meanings of "Ishi" or "Ishii" are "stone", "willpower" and "a doctor". Tone, intonation, and inflection and the sentence structure as a whole would play a very important role in distinguishing the meaning.

English is a low context culture language and requires more explanation in communication and less reliance on tone, intonation, and inflection when it comes to defining meaning. It is more simplistic. If the voice is loud and rough and awkwardly abusive, it is just as clear to say the sound signals warning or danger. Concerning language learning, a learner must understand that systematization is a must for mastery of the target language.

Giles and Ogay's (2007) "Communication Accommodation Theory" claimed that people put up or regulate their communication styles to other people through divergence and convergence. Perhaps the researcher due to his mobility from culture to culture has learned to adjust his style through the usage of his senses and imitation to learn communication with people in culture from different sects by quickly learning to imitate them and make himself feel as if he is part of the group. Thus, the researcher can adopt and adapt the tone that best fits the culture that he is exposed to.

Undeniably, Nolan (2014) suggested that the role of intonation in passing on attitude is difficult to describe and a person's attitude is disguised in their emotional condition. Whether formal, polite, or casual, basically attitude controls intonation. Hymes (1972) stated that styles of speech may be used in various situations and events. These styles can also be observed in written discourse. The researcher has observed that the Japanese are very polite and generous in the use of "thank you" in written discourse whereas Americans are just casual. In conversations, the Japanese are polite and formal based on their age and status or class rank.

Meanwhile, Americans and even Filipinos are very much casual and sometimes even emotional. This notion of politeness in Japan seems that it is even encoded in the moral attitude where they show verbal gratitude to receiving a gift so often as to the point when the gift might have been given to the month or even years ago and they would still thank the person who gave the gift. They would use the unspecified date expression such as: "Konaida Oishi caki present moratano arigato gozaimashta" meaning, "Thank you for giving me a delicious cake the other occasion". In the Philippines, the researcher observed, thank you maybe said initially but never repeated 
as often as he has experienced in Japan. This does not make the Filipinos less appreciative at all. Verbal gratitude and nonverbal gratitude are both styles used by different societies and only understood by the members of that specific society. Therefore, the researcher believes that styles of speech that may be used in various situations and events are culturally connected.

Nygaard \& Lunders (2002) suggested that the expressive tone of voice can be interpreted individually as a verbal substance and be incorporated in the breakdown of the entire statement. For instance, when a speaker says "I am very excited" in a monotonous tone could show sarcasm as the meaning would be "I am very bored." Depending on the context culture of a language group, the researcher found that Japan and the Philippines belong to a very high context culture and reduces or even rules out the notion of "emotional transcriptions". This phenomenon of showing no emotional tone is somehow transparent after the completion of Junior high school in Japan and could be related to cultural values heavily placed on the learners or could be a result of puberty in high context cultures. The Japanese call this attitude of culture "Honne to Tatemae" which is very hard for low context cultured foreigners to understand. It is the notion of keeping one's internal feelings in when one is exposed to outside or public. However, this does not mean that the Japanese show no emotions and that "emotional tone of voice" is not apparent or does not exist in the Japanese language. It simply means that there also exist parts in some culture's language(s) that may not indicate an "emotional tone of voice". Therefore culture, in these cases, seriously plays an important role in learning the target language.

Once learners can differentiate the meanings of the learned vocabulary with a crystal-clear understanding of the aforementioned features of speech, they are now in the process of making concepts in their minds on what and how to say their ideas. Moreover, they also make new concepts and meanings as they are exposed to the target language and so, conceptualization takes place.

\subsection{Concept vs. context}

Concepts are like the air people breathe; they are everywhere. They are essential to their existence, but learners rarely notice them until the concept is analyzed. Like the ABCD song that a non-English speaker was taught to sing without realizing the notion of its concept. Nature does not give us instructions on how things are to be conceptualized. Learners must create that conceptualization, alone or with the guidance of others. Once done, they integrate the concept into their schema, as no concepts stand-alone (Toastmasters Int'l., nd.).

English numerals like 12 and 20 evidently "represent individual concepts" than its Japanese counterpart 12 is 10 (ju) - 2 (ni) or "ju-ni" and 20 is 2 (ni) - 10 (ju) or "ni-ju" where numerals are read in a grouped manner. This is precisely the rationale as to why the Japanese numerals are so clear. However, to non-Japanese speakers who use different terms in counting it is confusing (Booth, 2017).

Going further with this idea that language is a practice of abbreviation among folks and members of social groups and that we get our notions of "meaning" from agreements, if learners cannot understand a concept, then a "demonstration of concept" can help learners to apprehend it; just like the Japanese counting method (Booth, 2017).

According to the linguistic relativity principle, one's native language influences thought; where memory and view are inclined by the available words and expressions of that language. The researcher left his homeland, Iran at the age of 11 and learned to adjust to a new language which became his "new native language." Did the "first language" affect the usage of the "second language"? The researcher feels it did not, as he had to adapt to a new environment and culture and adjust to his surroundings which were different or alien in every aspect from his original homeland. This required a definite change of perception and absolute immersion.

The researcher re-educated himself in later years in his mother tongue but clearly, he had adopted the new North American culture which has had a great influence on his thoughts and memory perception. While he admits that he has a more global view of the world, he has lost the localization part of his mother tongue, and being in Japan for many years he has lost the more up to date expressions of his North American homeland. This does not make him a lesser native speaker. However, it does limit his ability to understanding local expressions and meanings to words used in places where he was raised. As the saying, "Use it or lose it" may fit the notion that language is a living thing only to be used as a tool for communication. Through interaction with other natives, self-awareness, and media exposure has helped the researcher increase his language skills but it should be noted that it is practically impossible to simultaneously know several languages as equally. Anyone claiming that they can speak several languages accurately would not be able to do so for the simple fact that language changes in time and space and one cannot easily keep up with time and space in one body. All three languages that the researcher can speak are not spoken on an equal level of proficiency.

Those who claim to be able to speak numerous languages have not proven by any means other than saying a few expressions to impress the observer and not shown any tangible proof that they have mastery in all the acclaimed languages. There is no solid proof of any proficiency test or exam to show absolute mastery of a language. In the researcher's view, English stands higher than the other two languages he can communicate in due to its use over the other two.

This implies that factual perceptions are more to do with agreements in language among many (conventions). 
If this were not the case there would be implications. People say "the blue of the sky" or "the brown of the table" so that they get on with life and make progress, otherwise, everyone will be putting his or her slant on things between mind and world, where the self participates in something much bigger than itself, ruling out subjectivism from early on (Booth, 2017).

\subsection{Evolving words and neologisms}

Upon reaching accuracy and fluency, any language learner has come to another phase of language evolution called neologisms (Lehrer, 2003). Things that affect culture either by events or through technology give cause to the invention of new words or neologisms. A recent example of such a domain is the electronic communication and internet which as a result of their existence have caused the creation of many neologisms (Ayto, 2006). Because of trends, new processes, and concepts, this phenomenon of word-formation is rapidly increasing.

However, some of these "new words" are not yet in the lexical database therefore retrieval of meaning is a challenge especially to the older generation. Nonetheless, due to the plethora or abundance of text being produced recently, especially in the online world such as blogs and vlogs, meanings of these words do not require manual analysis (Cook, 2010).

It is claimed that every day a minimum of 10,000 new words are created in English; though, most of these words never become recognized forms and accepted in recognized dictionaries. Yet, despite its difficulty to estimate the total number of neologism (accepted or not), it is obvious that several "new words" are added in the English language and other languages every year (Metcalf, 2002).

The vocabulary can be categorized into the "general and the main vocabulary". Lin, M. (2013) argued that the main vocabulary is the nucleus element of the words and it has existed for a longer phase of time and could be distinguished as stable, commonly used, consistent and productive. Nevertheless, general vocabulary could be characterized as "common vocabulary", "archaisms", "loanwords", "dialectal vocabulary", "specialized vocabulary, and so on" where "neologisms" can as well be classified. It is important to note that general and main vocabulary is "exchangeable" together with their meanings (Liu D., 2010).

Millennials" are always on the pursuit of rareness, diversity, new styles, trends, and new features in the target language that they have mastered. People of this generation prefer "colorful and rich language styles" including "unique and lively language forms" (Yang, 2002). Most neologisms are not the product of discoveries, but Jin (2007) stated that it is a new flavor to concepts or existing syntax. Therefore, the craving for the "freshness of languages" frequently is a major motivation on the birth of newly coined words.

Words like "frienemy/frenemy", "netizen", and "char" are only a drop of the countless neologisms that have existed.

Based on Collins Dictionary, "frienemy/frenemy" (n): is a portmanteau from (Friend + Enemy), which refers to "a friend who acts like an enemy or an untrustworthy friend". Simply, it is "an enemy in the guise of a friend or a partner", who is at the same time an opponent and competitor (Mostafa, 2013). The following sentences show the usage of the word:

"We were frienemies for a long time ago!"

"There are ways to recognize a frienemy."

Another trendy word that is widely accepted and used online is the term "netizen" (n): a combination of "Internet and Citizen" which is a modification of citizen; it is an excerpt from the Internet, (net) and the end part of the citizen, (izen). It is an unusual combination where mutually "the last parts of both of the words" are utilized. The word refers to someone who interacts with others on the Internet and or is a citizen of the Internet. "A regular or a routine consumer of the Internet, or someone who spends a great amount of time on the internet, aggressively occupied in online communities practically all day and night is called a "netizen". Mostafa (2013) provides some examples:

"According to survey, $90 \%$ of netizens are Americans."

"There is a day in China called the netizen day."

"In some ways many people in the world are part of the netizen family since people use internet communication to connect to others and see this notion of being a netizen as safer and being in a better world."

Scholars emphasize a convincing case in the significance of studying blended neologisms in the study of languages, to assist and eliminate doubts. It is important to note that creative neologisms show a great deal about important points of word-formation. Knowledge of "creative neologism" can assist learners to understand the development of diverse meanings (Brdar-Szabó \& Brdar, 2008).

Filipinos have given the English word "char" a new definition. Originally, Merriam Webster Dictionary defined char (n) as a kind of small-scaled trout with fair-haired spots; (v) to change to charcoal or carbon, usually by heat: burn or to burn slightly or partly scorch: like "The fire charred the beams". In the Philippine setting, "char" is a variant of "charot" (a gay expression which means: joking, just kidding or said after a statement if it is meant to be a joke and not true). The word started as gay-lingo, but it is now used by the general public. It is also often said when one is telling the truth but does not want to be taken seriously. Like so: "I love you......char!" (Laureta, 
2017).

Although people will not borrow a word from other languages, they can still employ ways to deviate the sense of language or rules of sentence structure to express special emotions or feelings using language as a tool to communicate. All languages can contain their deviations and never constant. Meaning and treatment of neologisms can "grow and increase" constantly (Lin, 2013). Language is vigorously developing. Everything is reflected in the words people use to talk about themselves and their environment. Language undergoes metamorphosis together with the world. "Like the growth rings of a tree, the vocabulary of humanity bears witnesses to the past. Words and expressions are created, enjoyed its novelty, and eventually die or find their spot in the dictionary according to the fleeting or permanent usage they represent (Behera \& Mishra, 2013).

\section{Conclusion}

Systematization is the road to mastering the language and in so doing the requirements are learning grammar, conceptualization, and creativity. The learner at this stage is dependent on his or her motivation and advancement and the accuracy vary from learner to learner. Without the initial three stages of Localization, Imitation, and Practice which bring the learner to a fluency stage, there cannot be any movement towards Systematization or accuracy. It is assumed that the learner by the stage of fluency will either stop or move on depending on the goals he or she has in studying the target language.

Some who aim to master the language through proficiency exams tend to miss out on the real deal of mastering communication using the target language as a tool. As the saying goes, tools that are not used tend to rust and get eroded. A language that is not used tends to be forgotten or pass away. Therefore, the implications of systematization to language learning is that it would be useless if it was not carried out systematically from the stages of localization to Imitation to Practice. Effective language learning requires a lot more than learning the language system.

\section{Acknowledgments}

My deepest gratitude the Creator of all Good Thoughts, Good Words and Good Deeds as well as to the leaders of my university, Director/Owner Doctor Kunitaka Takagi, President Doctor Tsutomu Imaizumi, Vice President Doctor Hitoshi Maruyama and the heads of OT, PT and ORT departments for their support and positivity in allowing me to improve the students' language communication skills.

Great thanks to the students in Fukuoka International University of Health and Welfare for their participation in the voluntary questionnaire. Finally, I extend my gratitude to the friendly and cheerful people of the Philippines, who made my life more meaningful.

- Dr. Faramarz Samifanni

\section{References}

Arnold, D. H., Arnold, K., \& Arnold, V. (2010). Managing Ethical Risks and Crises: Beyond Legal Compliance. Beijing Law Review, 1(1), 1-6. https://doi.org/10.4236/blr.2010.11001

Ayto, J. (2006). Movers and Shakers: A Chronology of Words that Shaped our Age. Oxford: Oxford University Press.

Azar, B. (2007). Grammar-Based Teaching: A Practitioner ‘s Perspective. TESL-EJ, 11(2), 1-12. Retrieved 0222 , 2019, from http://www.tesl-ej.org/ej42/a1.pdf

Behera, B., \& Mishra, P. (2013). The Burgeoning Usage of Neologisms in Contemporary English. IOSR Journal of Humanities and Social Science, 25-35. https://doi.org/10.9790/0837-1832535

Beverly, A. H. (2007). The role of grammar in improving student's writing. Retrieved from from http://www.sadlier-oxford.com/docs/language/paper_chin.cfm.

Booth, M. (2017). On Language, Understanding and Meaning.

Brdar-Szabó, R., \& Brdar, M. (2008). On the marginality of lexical blending. Jezikoslovlje, 9(1-2), 171-194.

Chin, B. A. (2000). The Role of Grammar in Improving Student's Writing. Retrieved from https://www.researchgate.net/publication/265744608_The_Role_Of_Grammar_In_Improving_Student's_W riting

Clark, M. (2018). From Monotone to Moving: The Power of Voice Inflection. Retrieved from https://www.abstraktmg.com/outbound-lead-generation/sales-tips-for-lead-generation/the-power-of-voiceinflection/

Coleman, C. (2017). Using Inflections. Retrieved from https://sayitwell.com/using-inflections/

Cook, P. C. (2010). Exploiting linguistic knowledge to infer properties of neologisms.

Creswell, J. (2013). Qualitative Inquiry \& Research Design: Choosing Among the Five Approaches. Thousand Oaks, CA: SAGE Publications, Inc.

Crystal, D. (2003). English as a global language. 2nd ed. Cambridge: Cambridge University Press.

Derakhshan, A., Tahery, F., \& Mirarab, N. (2015). Helping adult and young learner to communicate in speaking 
classes with confidence. Mediterranean Journal of Social Science, 6(2), 520-525. https://doi.org/10.5901/mjss.2015.v6n2p520

Dwijatmoko, B. (2013). Foel_Syntax 2013.ppt.

Ellis, R. (2006). Current Issues in the Teaching of Grammar: An SLA Perspective. TESOL Quarterly, 40(1), 83107. https://doi.org/10.2307/40264512

Evan. (2016). The Importance of Inflection and Tone When Learning a New Language. Retrieved from https://briclanguage.com/importance-inflection-tone-learning-new-language/

Francis, W. S., Romo, L. F., \& Gelman, R. (2002). Syntactic structure, grammatical accuracy, and content in second-language writing: An analysis of skill learning and on-line processing. Advances in Psychology, $317-$ 337. https://doi.org/10.1016/S0166-4115(02)80017-6

Giles, H., \& Ogay, T. (2007). Communication Accommodation Theory. In B. Whaley, \& W. S. (Eds.). Mahwah: NJ: Lawrence Erlbaum. Retrieved from https://core.ac.uk/download/pdf/147103741.pdf

Glasser, B. (1978). Theoretical Sensitivity: Advances in the methodology of grounded theory . Mill Valley CA: Sociology Press.

Haiman, J. (2002). Systematization and the origin of rules. In Studies in Language (pp. 573-593). https://doi.org/10.1075/sl.26.3.04hai

Harley, B. (2001). Freshmen, information literacy, critical thinking and values. Reference Services Review, 29(4), 301-306. https://doi.org/10.1108/EUM0000000006492

Harmer, J. (2001). The practice of English language teaching (3rd ed). London: Longman.

Hou, K., \& Na-Thalang, S. S. (2013). The Role of Grammar Awareness in Learning English Wh-Movement by Chinese L2 Learners. English Language and Literature Studies, 3(3). https://doi.org/10.5539/ells.v3n3p56

Hymes, D. (1972). Models of the interaction of language and social life. In J. J. (eds), Directions sociolinguistics: The ethnography of communication (pp. 35-71). New York: Holt, Rinehart \& Winston.

Jin, H. (2007). Xiandai hanyu xinci yanjiu Guoli zhengzhi daxue zhongwenxi shuoshilunwen.

Larsen-Freeman, D. (2001). Teaching Grammar. In M. Celce-Murcia (ed.), Teaching English as a Second or Foreign Language (3rd edn). Boston, MA.: Thomson/ Heinle.

Laureta, I. (2017). Filipino Gay Lingo Explained For The Rest Of The World. Retrieved from BuzzFeed: https://www.buzzfeed.com/isabellelaureta/i-love-you-char

Lee. (2005). A study of English grammar instruction in elementary schools in Taipei. Unpublished master's thesis, National Kaohsiung First University of Science and Technology. Taiwan.

Lefrançois, P., \& Armand, F. (2003). The role of phonological and syntactic awareness in second-language reading The case of Spanish-speaking learners of French. Reading and Writing: An Interdisciplinary Journal, 219246. https://doi.org/10.1023/A:1022874425314

Lehrer, A. (2003). Understanding trendy neologisms. Italian Journal of Linguistics, 15(2), 369-382.

Lin, M.-c. (2013). A new perspective on the creation of neologisms. Retrieved from https://revije.ff.unilj.si/ala/article/download/422/325/

Liu, D. (2010, 03). Going Beyond Patterns: Involving Cognitive Analysis in the Learning of Collocations. TESOL Quarterly, pp. 4-30. https://doi.org/10.5054/tq.2010.214046

Metcalf, A. (2002). Predicting New Words: the Mystery of Their Success. Boston New York: Houghton Mifflin Company.

Miller, F. (2009, 12 08). "NO SWEAT Public Speaking!". Retrieved from https://nosweatpublicspeaking.com/verbal-communication-2-inflection/

Mostafa, M. (2013). Trendy blends: A new addition to English lexicon. International Journal of Language and Linguistics, 1(4), 147-154. https://doi.org/10.11648/j.ij1l.20130104.18

Nazari, N. (. (2013). The effect of implicit and explicit grammar instruction on learners' achievements in receptive and productive modes. Procedia -Social and Behavioral Sciences, 156-162. https://doi.org/10.1016/j.sbspro.2013.01.051

Nolan, F. (2014). Intonation. Retrieved from www.ling.cam.ac.uk/francis/FN inton_prepub.pdf

Nygaard, L. C., \& Queen, J. S. (2002). Communicating emotion: Linking affective prosody and word meaning. Manuscript submitted for Publication.

Richards, J. C., \& Renandya, W. A. (2002). Methodology in Language Teaching: An Anthology of Current Practice. Cambridge: Cambridge University.

Saaristo, P. (2015). Grammar is the heart of language: grammar and its role in language learning among Finnish university students. In E. J. In J. Jalkanen, Voices of pedagogical development - Expanding, enhancing and exploring higher education languag (pp. 279-318). Dublin: Research publishing.net. https://doi.org/10.14705/rpnet.2015.000296

Saint Joseph College, C. f. (2009). Language, Tone, and Audience. Connecticut. Retrieved from http://ww2.usj.edu/PDF/cae/toneaudience.pdf

Schulz, R. (2001). Cultural differences in student and teacher perceptions concerning the role of grammar 
instruction and corrective feedback: USA: Colombia. The Modern Language Journal, 85(2), 244-258. https://doi.org/10.1111/0026-7902.00107

Sharma, H. (2017). What linguistics can teach us about language learning. Retrieved from https://www.worddive.com/blog/what-linguistics-can-teach-us-about-language-learning/

Strunk, W. J., \& White, E. (2000). The Elements of Style. (Vol. 4). Allyn and Bacon.

Toastmasters Int'l. (nd.). Retrieved from Westside Toastmasters, For Public Speaking and Leadership Education: http://westsidetoastmasters.com/resources/thinking_tools/ch06.html

West, P. (2016). Accuracy vs Fluency in TEFL. Retrieved from How To Teach English,Language Skills, Linguistics: http://www.icaltefl.com/accuracy-vs-fluency-in-tef

Yang, H. (2002). Hanyu xinciyu yanjiu. Harbin: Heilongjiang jiaoyu chubanshe.

Yulianto, O. V. (2014). The Use of Syntax in Improving Students' Grammar in Writing. Retrieved from ww.academia.edu/6195743/The_Use_of_Syntax_in_Improving_Students

Zalaghi, H., \& Khazaei, M. (2016). The Role of Deductive and Inductive Reasoning in Accounting Research and Standard Setting. Asian Journal of Finance \& Accounting, 8(1), 227-239. https://doi.org/10.5296/ajfa.v8i1.8148 